\title{
Amanda Berenguer: géneros entretejidos
}

\author{
Dovilè KUZMINSKAITĖ \\ Universidad Complutense de Madrid
}

\begin{abstract}
RESUMEN
Este trabajo analiza la poesía visual de la poeta uruguaya Amanda Berenguer publicada en su libro Composición del lugar (1976). El propósito de este artículo es reflexionar sobre la transformación del texto poético conforme a las estrategias creativas aplicadas y sobre la recepción del mismo.
\end{abstract}

Palabras clave: Amanda Berenguer, poesía visual, Composición del lugar.

\section{Amanda Berenguer: mixed genres}

\begin{abstract}
This paper analyses the visual poetry of Uruguayan poet Amanda Berenguer, published in her poetry book Composición del lugar (1976). The aim of the research is to investigate how the poetic text changes applying different artistic techniques and how it influences in the perception of the poem.
\end{abstract}

Keywords: Amanda Berenguer, visual poetry, Composición del lugar.

SUMARIO: 1. Introducción. 2. Escritura: el lenguaje (im)posible. 2.1. Selección de elementos. 3. Escritura: el $(\sin )$ significado. 3.1. Orden de la lectura. 3.2. El ritmo y el signo. 3.3. Espacio en blanco. 3.4. Sobreinterpretación. 4. Conclusiones.

\section{Introducción}

Hasta el siglo XX la poesía fue concebida como un texto sonoro y rítmico que tenía una forma y contenido precisos. Este concepto arquetípico empieza a cambiar en el siglo XX con la introducción del verso libre y con una producción creativa vanguardista, que, más que el contenido, empieza a valorar la forma y el lenguaje; esta actitud provoca la irrupción de la llamada poesía experimental. Curiosamente, la popularidad de este tipo de poesía cesa pronto, debido a su hermetismo y carácter lúdico. Sin embargo, esta se hace muy popular en América Latina, donde los movimientos experimentales son muy fuertes (por ejemplo, el grupo Noingandres en Brasil). En Uruguay la poesía experimental llega a su máximo esplendor a finales del siglo XX -aunque tiene precursores ya en el siglo XIX, cuando Francisco Acuña de Figueroa empezó a escribir sus ideogramas- y una de las mejores introductoras de este movimiento, es, sin duda, Amanda Berenguer. 
La poesía visual a lo largo de la historia de la literatura se ha entendido como un género marginal, conocido bajo el nombre más común de poesía experimental. Dada su supuesta marginalidad, este tipo de poesía se analiza siempre en términos dicotómicos: unos críticos reconocen la poesía visual como un tipo del discurso literario, y otros optan por dejarla fuera del canon literario debido a su supuesta falta de significado, puesto que esta parece querer borrar el límite entre significado y significante.

En primer lugar, para comprender el concepto de poesía visual hay que determinar el concepto de "texto". Tradicionalmente el texto se ha entendido como un conjunto de grafemas que se refieren a un objeto de la realidad; el lector, en este caso, es aquel que tiene que descifrar los grafemas y establecer el significado. Sin embargo, hay otra manera de comprender la palabra "texto": aquello que establece Roland Barthes, que afirma que el texto es un tejido y hay muchos tipos de texto, pues un objeto visual también puede ser comprendido como tal (Barthes, 2002: 137). Aplicando este concepto de texto llegamos a la conclusión de que la poesía visual también es un texto, pero peculiar, porque exige otro tipo de mirada; ya no hay solamente que reconocer y descifrar, sino también interpretar; tal como lo explica Noé Jitrik, el lector tiene que ser también el crítico (Jitrik, 2002: 322).

\section{Escritura: el lenguaje imposible}

Composición del lugar (1976) es un libro de Amanda Berenguer que introduce diversos juegos formales en su poética. Es un libro singular por su estructura, dado que aquí el lector se encuentra no solo con poemas visuales, sino con variantes de un mismo poema: todos los poemas tratan el mismo tema -la puesta de sol sobre el mar en distintos días-. Amanda Berenguer coloca a su lector en una posición peculiar, al margen de dos géneros: en primer lugar, se da un texto "convencional" y también se dan dos textos visuales desarrollados conforme a distintas estrategias creativas (se introducen símbolos matemáticos, juegos con diferentes tipos de letras y su colocación en el espacio, etc.) ${ }^{1}$. En el primer poema, por ejemplo, titulado "Poniente del sol sobre el mar del jueves 24 de febrero de 1972", la manera de colocar tres textos que tratan el mismo tema uno al lado del otro produce una cierta redundancia y un efecto tautológico, que a su vez implica que no es el contenido de los poemas lo que importa en este libro, pues observamos una separación en el acto de decir y el contenido de lo dicho:

1 Curiosamente, un juego parecido es desarrollado por el poeta uruguayo Ernesto Cristiani (1928-1989), que también utiliza la misma temática, pero él da un paso más adelante: coloca cada frase en un cuadro, y así acerca sus poemas más a lo visual que a lo escrito. 

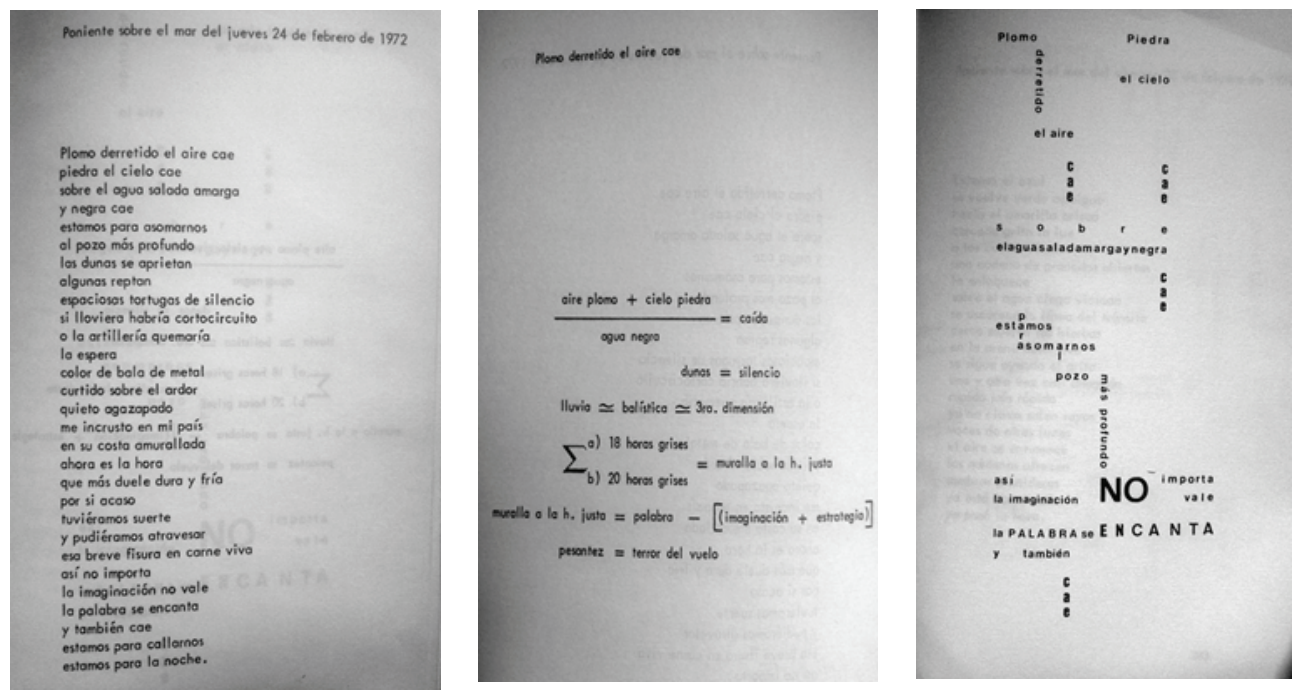

Este tratamiento de la forma evidencia la desvinculación con el modo descriptivo $^{2}$. Es decir, el lenguaje se entiende como un objeto cambiante que se encuentra en un constante movimiento, algo que vale por sí mismo y no por su contenido; con lo cual se da una clara ruptura con la referencialidad tradicional. Sin embargo, se puede observar, que este tratamiento de la forma en Amanda Berenguer es más que un juego: es una búsqueda del lenguaje, incluso, se podría interpretar como una desconfianza en este, debido a que la forma "verbal" es incapaz de hablar al lector, por lo que se hace necesario experimentar con ella. Este tipo de lenguaje mixto, de una cierta manera, deshecho, ya no puede "imponer una dictadura sobre su consumidor" y decidir "lo que las palabras deben, pueden y quieren decir" (Foucault, 1993: 11). El que elige el significado, en este caso, es el lector; el lenguaje mixto de la poesía visual adquiere una cierta neutralidad que no tiene el lenguaje convencional: la lengua de Amanda Berenguer ya no sirve para traducir el mundo.

\subsection{Selección de elementos}

Sin embargo, no deberíamos pensar en la poesía de Amanda Berenguer como un puro juego vanguardista. Lo que le importa a la poeta es jugar con los elementos pictóricos y verbales y ver cuánto se pueden acercar ambos lenguajes. Este trabajo es muy obvio en la selección de los elementos, por ejemplo en el poema "Poniente sobre el mar del viernes 11 de enero de 1974", donde observamos el paso de un texto "tradicional" extenso, a una reducción verbal total donde solo quedan unas

${ }^{2}$ La propia poeta dice, que "la palabra es un objeto sin fondo, una superficie profunda, un grafismo significante" y habla sobre la "poesía cinética" (Berenguer, 2002: 278) 
cuantas palabras -las más importantes- en combinación con signos gráficos y espaciales.
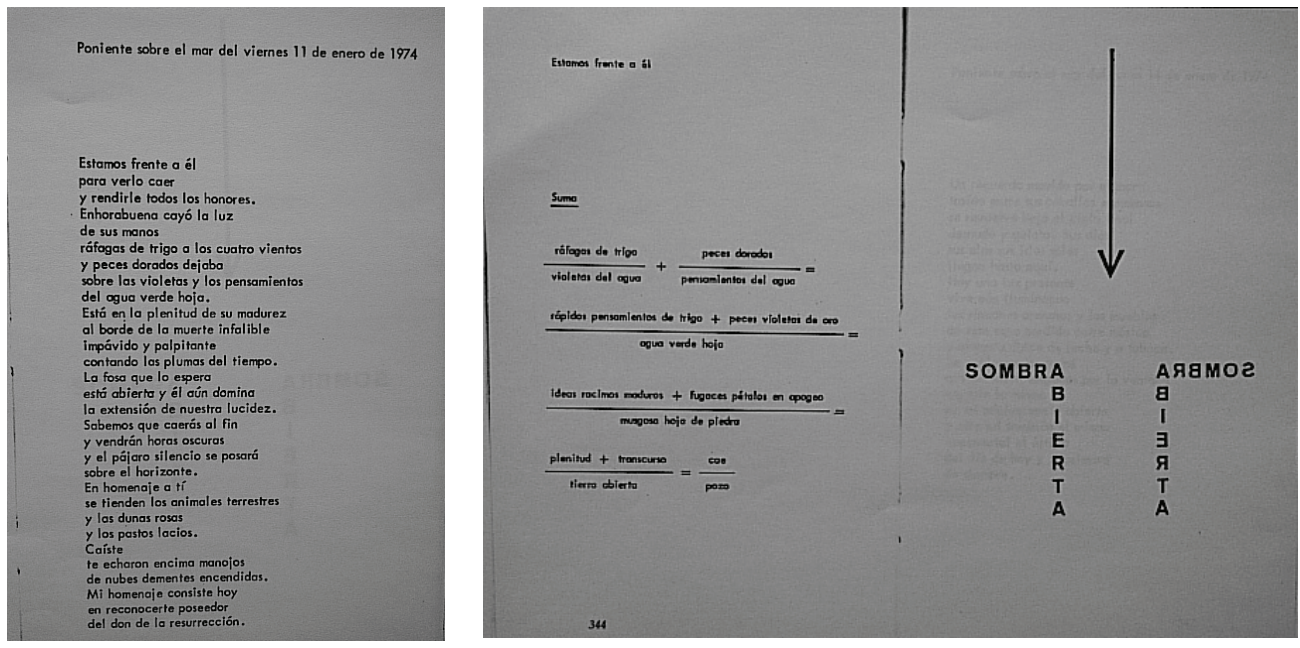

De esta manera, la poesía visual con sus estrategias se acerca a los discursos de la publicidad, que Roland Barthes analiza en su artículo "Retórica de la imagen", donde se habla sobre el texto como soporte del lenguaje pictórico, dado que este siempre se apoya en los conocimientos lingüísticos (Barthes, 1972: 2).

\section{Escritura: el (sin)significado}

\subsection{Orden de la lectura}

El mayor problema con el que se encuentra el lector de poemas visuales es, sin duda, cómo descifrarlos. Mientras que percibimos el lenguaje verbal como una serie de símbolos que sabemos interpretar aplicando ciertas herramientas (es un código que conocemos), el dibujo lo percibimos como una mancha (Jitrik, 2002: 315): es decir, la mirada hacia un texto verbal es más analítica y la mirada hacia un dibujo está más relacionada con una impresión; lo que se conmueve en el lector de poesía visual pertenece a dos sectores diferentes: la lógica y la emoción.

José Luis Pardo titula su artículo "Leer no es ver", teniendo en cuenta que lo que vemos, no lo podemos leer, y lo que leemos, no lo podemos ver; es decir, para percibir el poema visual el lector -aunque este término no es el más adecuado, Foucault lo cambia por "mirón" (Foucault, 1993: 37)- tiene que encontrar coherencia entre dos estrategias completamente distintas -dice el mismo autor que "se hace ver mediante la semejanza y se habla a través de la diferencia" (47)-. Para obtener el significado de un texto "verbal", lo denotamos, y mirando el dibujo en primer lugar, connotamos para luego poder denotar: el dibujo lo entendemos como una totalidad a la que aplicamos nuestras nociones sobre el mundo. No es posible 
aplicar las dos estrategias a la vez: "esta misma cosa que se ve y se lee está callada en la visión y oculta en la lectura", dice el pensador francés (Foucault, 1993: 36), quien también reflexiona sobre la importancia de la mirada superficial en el proceso de entender un poema visual. Es importante, por tanto, entender el verso no solo como algo que se compone de palabras, sino como un objeto mínimo, porque la palabra en muchos poemas visuales pierde su significado.

Además, la poesía visual exige otro orden de lectura. Esperanza López Parada, en su artículo "La condición de lo visible: el poema", se refiere a la importancia de la contemplación (López Parada, 2003: 209); sin duda, la percepción de la poesía visual exige otro tipo de "lectura": en primer lugar, hay que leer la totalidad y, en segundo lugar, leer las partes. La incoherencia entre el proceso de lectura y el proceso de escritura nos lleva a la ruptura tanto con la poesía como con el dibujo: la poesía visual es un antipoema y, a la vez, un antidibujo.

Sin duda, Amanda Berenguer nos lleva más lejos. Ella introduce la primera variante de cada poema, la variante "tradicional" a partir de la que se desarrollan sus otras versiones; éstas, a su vez, tienen ciertas características propias, dado que en algunas se utilizan los símbolos matemáticos y en otras se aplican las estrategias creativas que son más cercanas al dibujo y las artes visuales. Es decir, el lector puede intuir que la elección de los símbolos no es casual. Entonces ¿cómo deberíamos interpretar el poema visual: como un texto único, como un tríptico o un ciclo de poemas o como tres textos distintos?

\subsection{El ritmo y el signo}

En la poesía tradicional siempre ha sido muy importante el ritmo (Barthes, 2002: 87-88). Este no deja de ser importante también en la poesía visual, pero su importancia es diferente, dado que hay dos tipos de ritmo: el ritmo de las palabras y el ritmo del dibujo. En el caso de Amanda Berenguer esta diferencia se ve claramente en algunos poemas como "Poniente sobre el mar del sábado 11 de marzo de 1972". Mientras un texto convencional tiene una línea rítmica, el texto visual tiene dos: una que se produce leyendo los poemas y otra, la que impone el ojo: 

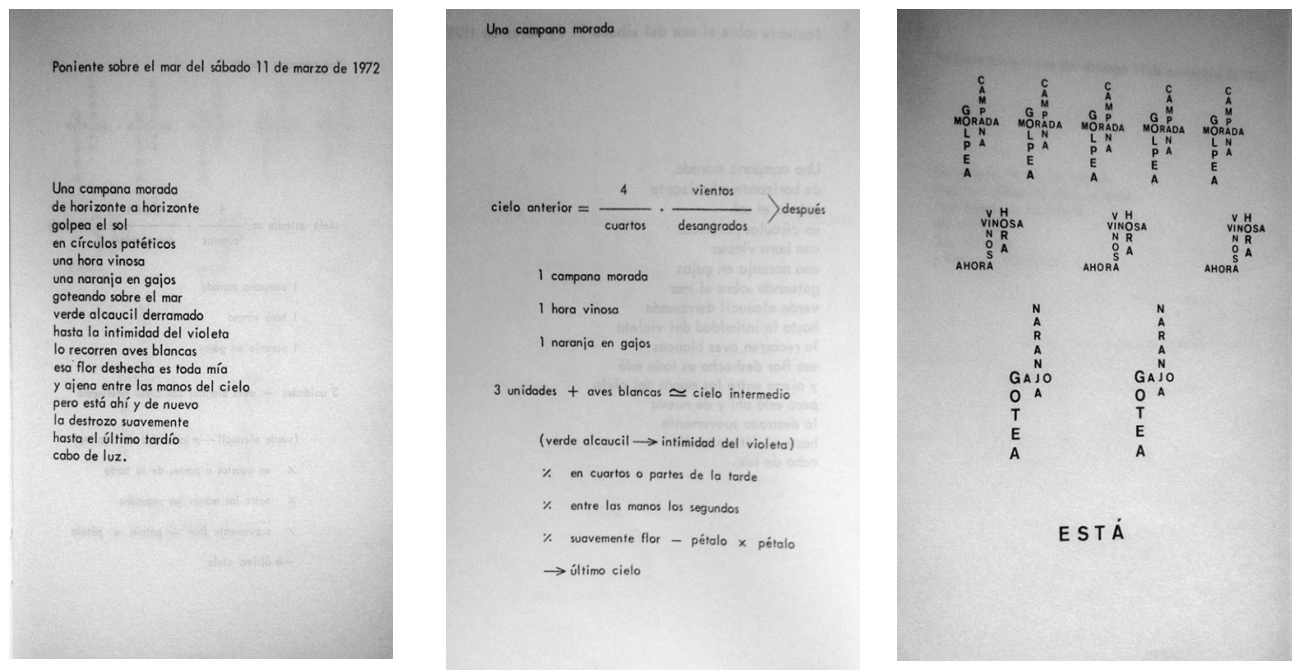

El texto visual es un texto que tiene múltiples sentidos, porque es un texto que está abierto al lector y exige su participación. Afirma Barthes que "el signo clásico es una identidad cerrada cuyo cierre detiene el sentido, le impide temblar, desdoblarse, divagar: ocurre lo mismo con el texto clásico: cierra la obra, la encadena a su letra. La clava en su significado" (Barthes, 2002: 138). Es decir, el texto clásico en sí, es un signo único que tiene su referente en la realidad. En cambio, el signo del discurso visual siempre es ambiguo y, además de la perturbación que produce en el lector, evoca más significados posibles. Podríamos pensar en el concepto de catarsis de Aristóteles; dado que la poesía visual apela a más sentidos en el lector, la catarsis también es mayor. El texto visual es un continuum de significados sin fin, que depende de cada lector y el dibujo, en el caso de la poesía visual, no ilustra, sino que prolonga el significado (Foulcault, 1993: 36).

Por lo tanto, hablar sobre el problema del significado de la poesía visual y la pluralidad de significados es un tema clásico. Pero también hay que pensar más en profundidad: ¿qué es lo que intenta decir la poesía visual (si es que intenta decir algo)? ¿Nos habla de la realidad o del lenguaje? ¿Desea Amanda Berenguer explicarnos cómo es la puesta de sol? Es muy llamativo lo que Belén Gache dice en su libro Escrituras nómades. Del libro al hipertexto (2006), donde habla sobre la poesía como un intento de encontrar imágenes para expresar vacío y silencio. Esto es muy útil si hablamos sobre la poesía visual de Amanda Berenguer, porque sus poemas, curiosamente, al mismo tiempo tienen y no tienen un referente en la realidad: a primera vista el poema habla sobre la puesta de sol, pero, en realidad, la poesía de Amanda Berenguer habla sobre la escritura, con lo cual el texto es autorreferencial y el signo, por tanto, está vacío. 


\subsection{Espacio en blanco}

Como dice Johanna Drucker, los poetas de la poesía visual entienden el papel en blanco como un espacio (Drucker, 1996: 42). Esta idea los lleva a pensar en cómo utilizarlo para enfatizar el poema y en cómo acercar dos espacios: el del poema y el de la página, y, además, el espacio en negro y el espacio en blanco. En la poesía visual la manera de organizar el discurso es muy importante, sobre todo porque precisamente la forma del poema es el primer aspecto que el lector percibe y a partir del cual se desarrolla posteriormente la lectura del poema. Esta importancia del papel como espacio se debe, obviamente, a las técnicas pictóricas. Como afirma Ángel Crespo y Pilar Gómez Bedate:

Los espacios en blanco forman un solo cuerpo con los caracteres impresos y juegan un papel integrante de la intención poética. Lo que se pretende es introducir un efecto sinestésico, conmover de un solo golpe todos los sentidos del lector, utilizando para ello cuanta potencia expresiva pueda poseer la palabra, tanto en su significado semántico como en su representación escrita, tanto en su vertiente sonora como en su vertiente gráfica. (Bedate y Crespo, 2013: 39)

El espacio en blanco es aquel que da forma al discurso en negro y que, de cierta forma, determina cómo vamos a ver y entender el poema, sobre todo en aquellos poemas que no disponen de los símbolos pictóricos (como en el caso de Amanda Berenguer, las flechas u otros símbolos matemáticos) que todos somos capaces de reconocer. Uno de los ejemplos más claros lo constituye el poema "Poniente sobre el mar del sábado 4 de marzo de 1972", donde la manera de colocar los versos del poema sugiere el ritmo de la lectura $\mathrm{y}$, al mismo tiempo, provoca un sentimiento de dispersión, separación, lentitud, e incluso de caída; es decir, la manera de colocar los versos produce diversas emociones en el lector y el léxico sirve para enfatizar: curiosamente, el movimiento ya no es al revés, el "dibujo" en la poesía visual no es una pura ilustración, un suplemento, sino un miembro equivalente al discurso verbal.

\subsection{Sobreinterpretación}

Finalmente, al leer este tipo de poemas también nos encontramos con el problema de la interpretación de los mismos: por una parte, la interpretación y el entendimiento quedan en suspensión dada la dificultad de entrar al texto, pero, por otra parte, como el texto-dibujo es muy abierto y multiplica el sentido y las posibles interpretaciones, tenemos el problema de lo que podríamos llamar "sobreinterpretación", que sería un conflicto típico de toda obra experimental.

Por otra parte, no se puede hablar de la obra de Amanda Berenguer como se habla de un poemario completamente hermético, porque hay poemas donde el intento de comunicar es muy claro. Por ejemplo, "Poniente sobre el mar del domingo 11 de noviembre de 1973": 
No estuve. No vi. No existió.

Pasó otra ráfaga del día a la noche.

Pasó sangre por lo huecos

del corazón.

Soy más vieja

y hoy estoy más cerca. (Berenguer, 2002: 319)

\section{Conclusiones}

Si hablamos sobre el cambio que en la poesía visual se produce con respecto a la relación con la referencialidad, Belén Gache afirma que "hoy no encontramos ya el mundo detrás de las palabras. Detrás de las mismas encontramos más palabras" (Gache, 2006: 17). A esto también, y aún más lejos, lleva la poesía visual: detrás de la imagen no está el mundo que se quería reflejar, sino que hay otros discursos. La poesía visual de Amanda Berenguer nos habla también de la imposibilidad de conocer el mundo y del discurso como algo que se puede manipular y que, a su vez, manipula el lector.

El carácter polifónico de la poesía visual lleva a un destino que es frecuente: el sinsentido (pensamos en la escritora argentina Mirtha Dermisache, cuya obra se acerca al "grado cero de la escritura", debido que se basa en puro grafismo). En el caso de Amanda Berenguer este rasgo podría estar asociado también con la época en la que se publicó el libro: 1976, porque el año 1975 en Uruguay fue el año más represivo de la dictadura, con lo cual este sinsentido podría entenderse como un contra-lenguaje o un movimiento voluntario para alejarse de todo tipo de discurso y de realidad y crear así un nuevo mundo: el mundo de la escritura.

\section{BIBLIOGRAFÍA}

BARTHES, Roland.

2002 Variaciones Sobre La Escritura. Barcelona: Paidós.

1972 "Retórica de la imagen". En: Uruguay de las ideas: todos los textos: Barthes, R. Disponible en: http://www.uruguaypiensa.org.uy/imgnoticias/833.pdf [Consultado el 23 septiembre 2014].

BERENGUER, Amanda.

2002 Constelación Del Navío: Poesía 1950-2002. Montevideo: H Editores.

CRESPO, Ángel y GÓMEZ BEDATE, Pilar.

2013 Situación de la poesía concreta. Madrid: Libros de resistencia. 
FOUCAULT, Michel.

1993 Esto No Es Una Pipa: Ensayo Sobre Magritte. Barcelona: Editorial Anagrama.

GACHE, Belén.

2006 Escrituras Nómades: Del Libro Perdido Al Hipertexto. Gijón: Ediciones Trea.

JACKSON, K. David; VOS, Eric; DRUCKER, Johanna.

1966 Experimental, Visual, Concrete: Avant-garde Poetry Since the 1960s. Amsterdam: Rodopi

JITRIK, Noé y FERRO, Roberto.

2002 Linea De Flotación: Ensayos Sobre Incesancia. Mérida (Venezuela): Ediciones El Otro, El Mismo.

LÓPEZ PARADA, Esperanza.

2003 "La condición de lo visible: el poema como gesto". Rosa Cúbica, núm. 23-24 (Invierno 2002 - 2003): La X en la frente, pp. 208-215.

PARDO, José Luis.

2014 “Leer no es ver". El país: Babelia, 01.03.2014, núm. 1162: pp. 12. Disponible en:

https://www.academia.edu/6263345/Leer_no_es_ver [Consultado el 23 de septiembre de 2014]. 